\title{
Imaginarios juveniles, cultura visual e instituciones culturales*
}

\author{
Jaime Martínez Iglesias**
}

\section{RESUMEN}

El objetivo de este trabajo fue describir las percepciones e imaginarios de un grupo de estudiantes de universidades privadas, y de algunos profesionales de instituciones culturales de Santiago, acerca de la influencia de estas en la formación de la cultura visual juvenil. La metodología es de tipo cualitativo, con un diseño interpretativo, descriptivo, microetnográfico, a través de entrevista semiestructurada realizada a jóvenes universitarios, y analizadas a través de una matriz de categorías y textualidades. Los principales hallazgos muestran que los jóvenes cuestionan los sistemas, programas de difusión cultural e imaginarios culturales, pero, a la vez, son capaces de reconocer las potencialidades que tienen los museos como entidades que facilitan la construcción de la cultura visual.

Palabras clave: Imaginario cultural, cultura visual, instituciones culturales (museos).

\section{Young imaginary, visual culture and cultural institutions}

\section{ABSTRACT}

The purpose of this work was to describe the perceptions and imaginaries of a group of students from private universities and some professional cultural institutions of Santiago, about the influence of these in the formation of young visual culture. The methodology type used is qualitative, with an interpretative, descriptive and microetnographic design through the use of semi-structured interviews for young university students from both genres, analyzed through a matrix of categories and textualities. The main findings show that young people question the systems, cultural diffusion programs and cultural imaginaries, but at the same time are capable of recognizing the potentialities that museums have as entities that ease the construction of visual culture.

Keywords: Cultural imagination, visual culture, cultural institutions (museums).

* "Imaginarios de un grupo de jóvenes universitarios de Santiago y de profesionales de museos, acerca de las instituciones culturales de la ciudad: Un estudio de cómo influencian la cultura visual juvenil" es un estudio patrocinado por el Programa de apoyo al Desarrollo de Proyectos de Fondo Semilla de la Universidad Católica Silva Henríquez.

* Jaime Martínez Iglesias es Doctor en Artes Visuales y Educación. Académico de la Universidad Católica Silva Henríquez. E-mail: jmartinezi@ucsh.cl 


\section{Introducción}

Desde la relevancia y actualidad de lo visual, se pretende hacer un aporte real al conocimiento y comprensión de la cultura visual y los imaginarios urbanos de los jóvenes en relación con la educación no formal. De algún modo esta cultura movilizaría hacia la adopción de imaginarios en relación directa con la realidad de las instituciones culturales, que surgen de la interacción espontánea como una narración, pero muy pocas veces son formulados explícitamente o de una manera completa. Poseen una estructura cognoscitiva moldeable y cierto grado de permanencia, no obstante, pueden desaparecer. Lindón (2007) plantea que la construcción de un sistema social dado se fundamenta en marcos de referencia que se muestran en los imaginarios sociales, cubriendo los espacios de respuestas esperadas. Por lo tanto, esta propuesta busca relevar aquello que no se habla o se da por sabido entre los jóvenes, y que no pretende ofrecer alternativas que fundamenten las decisiones educativas, culturales o sociales, sino que proponen una conversación más amplia y profunda sobre las políticas y las prácticas, tratando de desvelar aquello que se suele dar por hecho y que se naturaliza (Hernández, 2010).

Se considera que los centros de enseñanza, el espacio urbano y las instituciones culturales educan por sí mismos en la cultura visual de los jóvenes. Dicha ambigüedad es problematizada críticamente a través de los resultados de esta investigación, patrocinada por el Programa de apoyo al Desarrollo de Proyectos de Fondo Semilla de la Universidad Católica Silva Henríquez. Para ello, se revisan las percepciones e imaginarios de jóvenes universitarios y de profesionales de museos, acerca de las instituciones culturales, la cultura juvenil, la cultura visual, la accesibilidad a la cultura, la participación y la identidad, entre otras.

Cabe señalar que los imaginarios juveniles dan soporte a la construcción de las realidades sociales-culturales, favoreciendo modos y espacios para la formación de la cultura visual. La forma y el fondo de estas relaciones podrían revelar las dinámicas, relatos, discursos y manifestaciones culturales que los participantes van demostrando en su vida diaria. Las actitudes, juicios, prejuicios y conocimiento 
juvenil respecto de lo que podría llamarse cultura visual, devienen de un conjunto de percepciones fragmentarias que se construyen en la educación no formal. Si la escuela no atiende o no da suficientes garantías para ello, entonces, qué rol les cabe a las instituciones culturales en el desarrollo de las mismas. De ahí el interés por conocer cómo los jóvenes ven a las instituciones culturales y la relevancia que les atribuyen como agentes influyentes en su cultura visual (artes visuales, visualidades del mundo digital, historia del arte, iconografía urbana publicitaria, artefactualidades del diseño bi y tridimensional y arte contemporáneo, etc.).

De este modo, la relevancia de este trabajo se sustentó en la urgencia que existe a nivel país por conocer la relación que hay entre los imaginarios que los jóvenes tienen respecto de las instituciones culturales y cómo estas influenciaron la formación de su cultura visual o de las visualidades. También, permitió desvelar el rol que tienen en estos tiempos las instituciones culturales en su relación con los jóvenes.

A nivel de política cultural y educativa, esta información podría repercutir en la elaboración de estrategias para visibilizar y visibilizarse en y con los jóvenes a través de nuevos espacios de participación, canales de difusión actualizados, estrategias de consideración e integraciones amables e inclusivas, encabalgadas en las perspectivas actuales de participación, democracia y calidad de la educación.

Desde la definición del Consejo Nacional de la Cultura y las Artes (CNCA), instituciones culturales son todas aquellas instituciones cuyo fin es impulsar la cultura, la educación no formal, la alfabetización visual, la sensibilidad estética, la valoración del patrimonio y formación respecto de visualidades doctas y populares. Sin embargo, los teatros, las bibliotecas, los centros culturales, las galerías de arte no son relevados en la percepción de los jóvenes, asociándose la idea de institución cultural solo a los museos. Probablemente, esta percepción esté avalada por el imaginario cultural, histórico y por la tradición, ya que en las percepciones de los estudiantes y los profesionales de museos no se relaciona a las instituciones culturales con otros espacios que no sean los museales. Pese a que los museos no son visitados 
masivamente por los jóvenes, sí son capaces de reconocer en ellos su institucionalidad histórica.

\section{Marco Teórico}

\subsection{Política cultural 2011-2016}

La Política Cultural 20I I-20I6 actualiza materias como los ejes de creación artística, patrimonio cultural y participación ciudadana. Se supone una visión vanguardista y una resituación de los focos de interés extendidos más allá de la creación y difusión de las actividades artísticas y culturales, aportando en forma concreta al desarrollo de las personas y al fortalecimiento de una ciudadanía cultural. De este modo, el interés didáctico que concita la actualidad del eje patrimonio cultural se hace visible como elemento dinámico, capaz de generar la construcción de un sentido y una vivencia democrática, proporcionando elementos para una síntesis entre educación y patrimonio que se expresa a través del aporte de valores sociales, democráticos, humanos y en el ejercicio de una auténtica axiología cívica (Limón y Crespo, 2002).

\subsection{Juventud y experiencia en museos}

Los museos pueden desarrollarse cada vez más como espacios de aprendizaje si el equipo de colaboradores comprende la naturaleza del aprendizaje y la construcción del conocimiento, las razones por las que las personas asisten al espacio museal, las expectativas, intereses, creencias y marcos culturales de las audiencias (Rubiales, 2008). Desde luego, los museos tienen la capacidad de crear experiencias memorables, significativas y altamente contextualizadas. Es en estas vivencias donde se activan procesos de aprendizaje que permiten al individuo significar y resignificar las obras y objetualidades con las que interactúa, por lo tanto, el museo habrá entendido su sentido cuando la posibilidad de comunicar sus bienes tangibles e intangibles se haya logrado. Obviamente, eso dependerá de la comprensión de los intereses, estilos y expectativas de las audiencias, en este caso, los jóvenes. 


\subsection{Educación y museos}

Tratar de entender a los jóvenes de hoy para construir aproximaciones al museo no tiene que ver con decirles que es una práctica fundamental para perfeccionar su cultura o para que sean educados, sino para establecer intercambios con ellos y mostrarles que, también, pueden conocer, descubrir, deleitarse $y$, principalmente, construir conocimiento (Cabral, 2008). La educación en los museos ha sido un tema estudiado con mucho interés, no siempre por iniciativas propias (aunque las hay), sino que como necesidades de investigación generadas por agentes externos, las que dan cuenta de una falta de coherencia entre las políticas y currículos de la educación formal y la museística. De igual manera, los resultados de estas investigaciones identifican un rol desperfilado y, en muchos casos, inexistente de los educadores de museo, que, en última instancia, son quienes deberían hacer cuerpo el currículo institucional y sus discursos. Quizás se deba a que el educador de museos carece de cultura académica o de políticas de intervención y proyección. Pareciera que más bien adopta los valores y mitos del museo, sabe qué enseñar y qué aprendizajes tendrá en cuenta. Con este bagaje y estas actitudes, busca construir una relación cultural con los usuarios.

Es posible ver en todos los museos, departamentos de educación, equipos de trabajo dedicados a llevar a la práctica los discursos institucionales, ideas y conceptos, sin tener un grado de participación relevante en la generación de los mismos. Por otra parte, y lo que parece más complejo, el vínculo estratégico entre educación/ currículo, educadores y público, carece de coherencia y consistencia. Así, con prácticas etéreas e inconsistentes, el museo se enfrenta a su tarea educadora no formal, que debe estar centrada en el hombre, hacedor y espectador del patrimonio, entendiendo la complejidad del término patrimonio que no solo hace referencia a los bienes culturales, sino también a otros bienes y símbolos, presentes en manifestaciones culturales intangibles (Jaramillo de Carrión, 2008).

Tratar de entender la educación en los museos no es tarea sencilla, porque no son instituciones educativas. Se han apropiado de conceptos y teorías educativas, con el afán de construir un modelo de trabajo desde el cual hacer extensivos al público el sentido y 
valor de sus colecciones. Al respecto, Padró (2005) señala que hay que tener en cuenta que la educación en los museos se constituye a partir de concepciones sobre enseñanza y aprendizaje, versión sobre la producción del visitante en el museo y las narrativas que afirma, contrasta, contesta, explora y/o legitima.

\subsection{TIC y educación museal}

Los nuevos sistemas han superado las barreras espacio-temporales, por lo que ofrecen la posibilidad de acceso permanente y desde cualquier punto del mundo; han sido capaces de integrar y popularizar diferentes formas de expresión artística, haciéndolas asequibles a todos; han convertido la aldea global en una ciudad digital; han abaratado los costes de producción y de difusión; han democratizado el arte (Bellido, 200I).

Algunas instituciones culturales como los museos y centros de arte en Chile y a nivel mundial, están haciendo uso regular de las tecnologías, ya sea en los modos de presentación a través de la web como así durante la visita. Pero lo que sin duda acapara las acciones es el uso inteligente que algunos museos han hecho de las redes sociales a través del desarrollo de aplicaciones para dispositivos móviles con lo que se enriquece la visita física y su posterior cruce experiencial a través de Facebook, Twitter o WhatsApp.

La llegada de las tecnologías a las instituciones culturales ha traído consigo una amplia gama de dispositivos para enriquecer la experiencia de visitar una exposición. En la Era de la TIC, las entidades culturales y las empresas tecnológicas necesitan trabajar más estrechamente con el fin de aprovechar las oportunidades que ofrecen herramientas como los códigos QR, entre otros.

\subsection{Cultura visual}

La cultura visual es una construcción cultural que se aprende, cultiva y que, por lo tanto, tendría una historia vinculada con la enseñanza del arte, las tecnologías, los medios de comunicación, las prácticas sociales de exhibición y los modos de ser como espectadores (Mitchell, 2003). Visto así, se puede extrapolar esta cultura como 
un medio para tratar de conocer y comprender los imaginarios sociales desde los cuales muchos jóvenes construyen su realidad y su mirada del mundo en el que vive. En consecuencia, adentrarse en estos espacios para conocer la cultura visual y los imaginarios juveniles, implica tomar contacto con una realidad veloz y siempre cambiante como las imágenes que les dan soporte. Es decir, esquemas construidos socialmente que permiten explicar e intervenir en lo que en cada sistema social se considere como realidad (Pintos, 2004).

\subsection{Noción de imaginario social}

El concepto de imaginario social es una expresión forjada por el griego Cornelius Castoriadis para referirse a la forma de concebir el mundo singular, que le es propio a una sociedad particular, en un momento histórico. Desde el punto de vista teórico, este concepto posee la condición de versatilidad y profundidad necesaria para comprender las sociedades modernas. De esta manera, alude a la producción ontológica de un modo particular de ser e instituye la corporización de un magma de significaciones imaginarias sociales que regula los discursos, las prácticas, los deseos y los sentires de un conjunto identitario de sujetos (Castoriadis, 2007). La interpretación que crea para sí una sociedad constituye su identidad; la interpretación interna de los decires/haceres de ese mundo creado por la sociedad genera una cadena de significaciones que configura la unidad magmática de las pautas de su específica organización social. El imaginario social, de este modo, es la configuración de significaciones históricas que permite que los sujetos pertenecientes a una sociedad distingan su propio mundo, del mundo de los otros, otorgándole una capacidad de alteridad, que los identifica y les permite autorreferenciarse.

\section{Metodología}

La metodología de la investigación es de tipo cualitativo, con un diseño interpretativo, descriptivo y microetnográfico. Los jóvenes entrevistados pertenecen a cuatro universidades de Santiago y representan cuatro carreras diferentes: Pedagogía en Artes Visuales, Educación Parvularia, Pedagogía en Educación Básica y Arquitectura. La muestra se complementa con dos profesionales del área de 
educación de dos museos de la capital. La recogida de datos se realiza por medio de una entrevista semiestructurada realizada a jóvenes universitarios. Los jóvenes participantes se identifican por las abreviaturas: Na, Fra, Ja, Car, Kat, An, Ro, Ca, Ka, Cam y las profesionales educadoras de museo entrevistadas son: Ve y $\mathrm{Pa}$. Por último, los datos fueron analizados a través de una matriz de categorías y textualidades.

\section{Resultados}

\section{Juventud e instituciones culturales}

\section{Las instituciones culturales de Santiago: Jóvenes y museos}

Si bien en la actualidad se ha ampliado el rol de los museos a la acción consciente de educar, trasmitir y comunicar, algunas de sus tareas históricas prevalecen. El museo sigue siendo un centro de comunicación en cuanto sirve de canal para que las diferentes sociedades trasmitan y comuniquen sus rasgos culturales a las generaciones venideras (Jaramillo de Carrión, 2008).

Tal como se mencionó anteriormente, siempre hay razones para que los jóvenes visiten los espacios culturales con periodicidad o cada cierto tiempo, visitas que están asociadas a motivaciones de diversa naturaleza, que es pertinente comentar.

Lo que se destaca de las respuestas dadas es que cada visita conlleva un fin de crecimiento personal que bien podría ser entendido como una práctica destinada a generar acervo cultural por el contacto y vivencia de diversos fragmentos y situaciones. Hay quienes señalan que los museos son fuentes de imágenes y conocimientos que movilizan construcciones visuales e intelectuales, ayudando a abrir la mente y a socializarlos. Ka señala que estos contactos le han permitido visitar en el "GAM una exposición de fotografía relacionada con Chile durante la dictadura militar, y conocer las casas de Pablo Neruda de Isla Negra y Valparaíso. No creo haber aprendido contenidos duros, fechas o nombres. De esas visitas me quedo con algunos de los elementos que definen a Chile, su historia, su gente, personas que han dibujado a nuestro país, como Pablo Neruda, que también 
me recuerda la pasión por vivir y el valor de las cosas simples de nuestro cotidiano". Asimismo, hay conocimientos y prácticas que ayudan a algunos a desarrollar mejor las últimas, ya que alimentadas desde la observación y contacto directo, "las cosas que logro ver o experimentar en personas siempre las utilizo, soy súper esponja en ese sentido. Cuando chico, "mi abuela pintaba caballos, por ejemplo, entonces después yo agarraba eso y a partir de ahí me movía con las temáticas que aplico” (An).

Por otra parte, las experiencias de contexto permiten a los estudiantes vivenciar las obras, tratando de reconstituir las experiencias y sensaciones que algún autor pudo tener al momento de su creación para así poder "relacionar cómo era la época en que se hicieron esas obras y por qué fueron relevantes (...), porque eran algo que estaba ocurriendo en el momento, y que de alguna forma a través del tiempo se perdió la intensidad de la obra” (An). De la misma manera, es reveladora la observación siguiente: "Me gusta la idea de pensar que, al estar frente a una obra de un artista famoso, estoy parada en el mismo lugar donde esa persona estuvo y al admirarlo eso es algo significativo" (Fra).

Otra de las razones que los estudiantes tienen para visitar los museos es la posibilidad de aprender arte contemporáneo con las obras en vivo. Esto les permite mejorar la percepción y agudizar la lectura técnica de las mismas. En esta dirección es notable la relación que establecen entre los productos museales, las emociones y los sentimientos. El corolario de estas percepciones se expresa, según Fra, en que "más que aprender algo específico, se enriquece la cultura general de una persona”. Esta lectura, también releva que no hay diferencias significativas entre los estudiantes de Artes Visuales y los de Educación Parvularia, ya que en ambos casos las razones para ir a un museo tienen que ver con unos fines específicos y por voluntad propia. Cuando eso sucede, la visita se hace más profunda e íntima, pues el nivel de compromiso consciente con la actividad homologa las diferencias de conocimiento, técnicas y disciplinares que pudieran existir entre visitantes. De ese modo, las visitas y las razones que las motivan son unos aspectos claves para el reconocimiento de elementos valorativos de la cultura visual. Hasta aquí, se puede vislumbrar 
que en los museos existen ciertas condiciones y alternativas para que los jóvenes puedan formarse en algunos aspectos de la cultura visual. Los requerimientos ante el mundo de las visualidades hacen necesario explorar otras áreas y los aportes a los saberes juveniles, ya que estos tienen un posicionamiento acerca de las instituciones culturales tipificadas por los museos en este caso. Desde allí, observan, proponen y emplazan, enfocados en las experiencias transmitidas, los aprendizajes y la idea del acceso a la cultura. Por su parte, los museos tienen su particular percepción de los visitantes, especialmente el público joven, y para ellos, aunque sea unidireccionalmente, se definen ciertas acciones y políticas.

Los visitantes son definidos y caracterizados por los profesionales de museos como amplios, de actitudes independientes, en búsqueda de identidad, universitarios y secundarios en su mayoría, gustosos de definir percepciones respecto al arte moderno, creativos, curiosos, abiertos a estímulos, dispuestos a escuchar, pero también dispuestos a intervenir, a generar creaciones. Estas características del público joven, hacen suponer que hay un germen potente tanto en lo motivacional, en la riqueza de los contextos y en lo que pueden aportar para el desarrollo de la cultura visual. La encargada de educación de un museo de Santiago menciona: "Depende mucho del trasfondo de las familias de donde vienen, si es una familia que le gusta el arte hay una historia personal que se refleja en su comportamiento en los espacios del museo. También tiene que ver con lo social, entonces, si tiene pares que les gusta asistir como público de un museo, probablemente va a ir con ellos" (Ve).

Cuando se preguntó acerca de tipologías de visitantes jóvenes, una de las profesionales de educación de museos señaló que había tres tipos de visitantes: los que tienen "alguna relación con el contenido museal por pertenecer a carreras o actividades afines (...), los que son visitantes permanentes, pero que no tienen ningún conocimiento acerca del arte y las artes visuales, encontrando en el museo un lugar para apropiarse de herramientas técnicas, sociales y discursivas que les permitan abrirse camino en el conocimiento disciplinar de las visualidades, y están aquellos que no visitan frecuentemente las instituciones culturales y que, además, pertenecen a campos 
disciplinares diversos, destacándose entre ellos los de Pedagogía” (Pa). Para este grupo los museos han implementado estrategias de fidelización, como el acompañamiento y la inducción a las diversas colecciones, instancias que les han permitido encontrar allí un espacio de exploración, contacto y referencia de gran valor para los jóvenes vinculados al mundo de las artes visuales y a las artes escénicas, etc.

En relación con las opiniones de jóvenes y profesionales de educación de museos, se puede suponer que este tipo de instituciones son un lugar donde es posible educarse en la cultura visual, sobre todo los centros educativos que tienen carreras relacionadas con lo visual, siendo el museo un complemento dinámico al espacio educativo. En este contexto, es posible reconocer una clara diferencia entre los estudiantes de Arte y los de Pedagogía, pues los primeros mantienen una permanente actividad ligada a lo cultural y a actividades creativas, por lo tanto la visita, el contacto y la participación es parte de la construcción del lenguaje y las maneras de entender lo visual y las visualidades desde lo profesional.

Por otro lado, los entrevistados que estudian Pedagogía manifiestan percepciones diferentes en relación con las actividades artísticas, pues estas no representan experiencias relevantes ni sustantivas en su formación disciplinar. De esto podría inferirse que la periodicidad de las visitas y el sentido relacional del aula universitaria con la sala de museo genera cierta cultura de integración de espacios, ya que, según manifiestan la mayoría de los entrevistados, en el museo se puede hallar un espacio de cultivo, formación y discusión de la cultura visual.

\section{Instituciones culturales y necesidades juveniles}

Los jóvenes perciben que las instituciones culturales no los consideran como capital humano válido al momento de diseñar sus programas, ignorando necesidades como la accesibilidad, la pertinencia de la oferta, el costo de la entrada, etc. Otra de las estudiantes entrevistadas menciona que se "necesita expresarse por medio de algo, los sentidos propios de la edad, y esto se puede hacer a través de la música, la pintura, la danza o el teatro, por ejemplo (...) los espacios para desarrollar dichas actividades son inaccesibles y caros" ( $\mathrm{Na}$ ). No se 
cuestiona que no existan programas institucionales, sino el formato de los mismos, dirigidos a otro modelo de visitantes, por lo general ficticio. Este tipo de prácticas de diseño e implementación a puertas cerradas no solo excluye, sino que denota "falta de innovación en los espacios, exposiciones que se transporten de un lugar a otro, que se acerquen, no que estén escondidas en museos y en espacios para cierto nivel económico (...) falta que vayan a los lugares donde están los jóvenes" ( $\mathrm{Ka}$ ).

Las instituciones deberían atender la construcción de estrategias de colaboración con discursos que potencien la identidad, la pertenencia y la educación, con vigencia y claridad conceptual en el tiempo, en especial, acerca de los nuevos lenguajes y estatutos de las visualidades y el arte contemporáneo. Según Ja, estudiante de Pedagogía en Artes Visuales, "los artistas contemporáneos que van al MAC (Museo de Arte Contemporáneo), o a otros museos, son muy subjetivos con su propio entendimiento de las cosas. Esto no da pie para construir ideas más definitivas para que los jóvenes nos sintamos más seguros. El arte contemporáneo está muy desvinculado de lo que puede llegar a ser el conocimiento de una persona joven (...) se está escapando de las realidades que puede llegar a entender una persona que no tiene cultura visual".

Estos dichos evidencian que las necesidades culturales de los jóvenes no son la primera necesidad de las instituciones culturales, por el contrario, buscan favorecer un cerrado círculo de artistas, expositores y público. Son pocos los museos que piensan hacia afuera, la mayoría lo hace para adentro, perpetuando el eterno imaginario social de entidad cerrada y elitista, ignorando que "los jóvenes hoy en día necesitan conocer tanto las nuevas tendencias culturales (...), como también aquellas que son parte de nuestra historia" ( $\mathrm{Ca})$.

Los jóvenes entrevistados sostienen que el acceso a la cultura, con independencia de la escuálida oferta que conocen, no los representa, pues lo poco que logran ver es inaccesible, tanto por la ubicación geográfica de los espacios, como también por los altos precios que se deben pagar en algunos casos. Así, queda explicitado en las palabras de $\mathrm{Na}$ cuando señala que "no es accesible la cultura o las 
artes para los jóvenes, ya que aún está muy ligada a las condiciones sociales, económicas y culturales de cada sujeto en relación con su entorno". Por otra parte, otros de los estudiantes sostienen que la cultura es accesible, agregando que solo falta interés e información actualizada.

Una prueba de ello es la agenda de la DIBAM en la cual se propone un nutrido panorama de actividades asociadas a todas las entidades agrupadas en la institución. Sin embargo, Ka comenta que "uno camina por la calle y los únicos afiches y mensajes que se ven son los que están en los paraderos, que casi siempre están rayados o son de exposiciones que pasaron hace mucho tiempo”. Esto podría significar que hay cierta comodidad en los jóvenes en cuanto a la tarea de exploración e información necesaria, quedando ello sujeto al azar o a las circunstancias informativas de la ciudad. Se puede deducir, entonces, que sí existe información sobre actividades, pero no sirve si no se conoce, como tampoco es eficiente "la operación de los dispositivos capaces de hacerla llegar a los jóvenes” (Ja).

\section{Lo que dicen los museos acerca del acceso cultural}

Si bien el acceso a la cultura es una necesidad, al mirar el mismo asunto desde los museos sorprende que estos reconozcan no tener programas formales de integración ni estrategias de contención, hasta el punto de no poseer "ningún taller, no tener ningún plan de acción para trabajar con los estudiantes jóvenes de Educación Media” ( $\mathrm{Pa}$ ), percepción que se complementa con lo que dice Ve, al mencionar que "actualmente no hay ninguna estrategia para relacionarse con público, porque los recursos son escasos”.

Sin embargo, cuando se trata de público universitario las cosas se dan de otra manera, apareciendo estrategias y actividades que buscan vincular y educar a través del acercamiento al mundo de las imágenes, con alfabetizaciones críticas de visualidades bi y tridimensionales relacionadas con el arte "para desarrollar en ellos la capacidad de reflexión y la capacidad de criticar desde las imágenes” (Pa), lo que permite indagar sobre lo que vemos, cómo vemos, cómo eso nos afecta, nos resitúa y nos ayuda a comprender cómo están construidas las representaciones en torno a la juventud. 
Con la excepción de estos acercamientos, en general, los museos consultados no cuentan con planes establecidos para el trabajo con público joven. De este modo, las experiencias con el mundo museal quedan sujetas a las circunstancias de las exposiciones emergentes y a las colecciones que se exhiben en forma permanente. Aun en esta precariedad es un aliciente para que muchos de los visitantes puedan ir construyendo un significativo aprendizaje en torno a la cultura visual, sobre todo, como lo menciona Pa: "lo nuestro es la pedagogía y sobre todo (...) tiene que ver con el juego, con la participación, con el conversar, con la reflexión".

No obstante, los dos museos consultados manifiestan a través de sus profesionales que hay una notable preocupación por la educación infantil y básica, destacándose programas de seguimiento centrados en el recate de la memoria histórica y la formación en el conocimiento del arte, con lo cual "el museo satisface esa necesidad de los contenidos curriculares, ya que calza muy bien” (Ve). Esta afirmación tiene que ver con que el currículo de Historia, Geografía y Ciencias Sociales de Educación Básica, el cual casi en todos sus niveles tiene contenidos que por sus características podrían ser abordados a través de los museos. En tal sentido, la labor educativa de los museos provee ayuda a promover aprendizajes más significativos en contacto con los objetos, lo que, sin duda, aporta a la construcción de la cultura visual. Los artefactos tienen un contexto, un discurso, que se puede leer desde la clave cultural de los visitantes. Se puede decir por lo tanto, que el concepto de cultura visual es el resultado de la conexión entre el objeto, el hecho y el sujeto, con su historia, referencia cultural, artística, su sentido, etc. Por tanto, tiene que ver con los significados culturales de por qué se produjo la obra, cuál era la intención y qué función comunicativa cumplía en su contexto (Hernández, 2010).

El tema de la educación de la cultura visual es relevante, pero exiguos los planes de trabajo que los museos presentan, lo que, sumado a una labor de acompañamiento poco fundamentada, merma las posibilidades de aprendizaje y construcciones sólidas. Por eso, llama la atención cuando $\mathrm{Pa}$ menciona que las tareas de acompañamiento están a cargo de educadores de museo provenientes de áreas afines, permitiendo relevar aspectos pedagógicos más que los disciplinares, 
"pues todas las instituciones culturales tenemos que empezar a abordar el tema, con educadores de planta y ojalá provenientes de una carrera universitaria” $(\mathrm{Pa})$.

Una de las profesionales entrevistadas menciona que otro aporte importante que hacen los museos son las instalaciones físicas y sus entornos, constituyéndose en un referente de diseño arquitectónico para los extranjeros, haciéndoseles más fácil y expedito el acceso que a los santiaguinos. Desde el punto de la cultura visual, este es un activo importante, pues hay un correlato entre exteriores e interiores del espacio arquitectónico, generando interesantes diálogos entre forma, recorrido, programas, objetos culturales y color, que invitan a habitar y a generar interacciones significativas.

Los museos han abierto sus puertas a personas ciegas, para ello han elaborado una metodología de trabajo capaz de suplir la carencia de visión con una cualificación del tacto, creando materiales de intervención y seleccionando ciertas obras que, por sus particulares características, se presentan como las más adecuadas para la actividad, iniciativa con la cual los museos buscan hacer efectiva la inclusión y la integración.

Las metodologías activas de alfabetización para niños son otro aporte significativo de las instituciones museísticas al desarrollo del pensamiento visual desde temprana edad. Esta práctica tiene componentes concretos para la educación de la cultura visual del futuro, por cuanto "les enseñamos a los niños desde pequeños a desarrollar la capacidad de percibir, la lectura visual, el pensamiento visual, pues no solo es ocupado en el mundo de las artes, sino que es una herramienta interdisciplinar" ( $\mathrm{Pa}$ ). Lo anterior se enriquece con la perspectiva de "transformar el espacio museal en un lugar de encuentro, desacralizando su aura de alta cultura para hacerlo asequible, para que no solo se pueda ir a dar un paseo en silencio y de manera individual, sino que a la vez pueda ser un espacio al que venga gente (...) que se encuentre, converse, se ría y dialogue acerca de lo que hay ahí, ayudando de paso a reconstituir la memoria y la identidad del lugar" (Pa). Se tiende a pensar en el museo como un lugar silencioso y solemne. Desde esa perspectiva, "es difícil pensar 
en cómo deberían ser las instituciones culturales (...), pues no existen muchas personas interesadas en ampliar su cultura visual” (Fra).

\section{La juventud y sus imaginarios acerca de las Instituciones Culturales}

Según Martínez (20II), los imaginarios como mecanismos de respuesta ante la construcción de la realidad social pueden ordenarse en cinco fases: adopción, acciones a las que impulsa, composición, proceso de cambio y acomodo permanente y vigencia o caducidad. En este sentido, la mayoría de los entrevistados tiene una percepción crítica acerca de las instituciones culturales. Esa construcción social está basada en un imaginario que a nivel colectivo y personal define un modo de verlas y entenderlas. Tal posicionamiento ante la realidad no solo les permite contestarse acerca del rol de las instituciones, sino también actuar en conformidad a ello. Esto hace posible que, a nivel general de las percepciones de los actores, no haya grandes diferencias de enfoque, incluso, coincidiendo la mayoría en varias de las opiniones.

Los jóvenes tienen un imaginario de las instituciones culturales como entidades desconocidas, que no trabajan para ni con los jóvenes, sintiendo que son ajenos a estas. "Tampoco logran crear mayores expectativas en los jóvenes, pues estos se siguen manteniendo al margen" $(\mathrm{Na})$. La situación de lejanía y marginación a la que alude este imaginario hace actuar a los jóvenes en concordancia con ello, reforzando el sentimiento de desarraigo y comprobando en cada situación la falta de interés por parte de los responsables de la actividad cultural. No es difícil imaginar que en un panorama así, la oferta cultural aparece como una entelequia, no creíble, no accesible y no participada. En consecuencia, desde este imaginario sería complejo entender o visualizar espacios para la construcción consciente y programática de la cultura visual intramuseal.

El imaginario de las instituciones culturales como entidades de poder, es otra de las construcciones que relatan los jóvenes, pues la formación de audiencias apoyadas en discursos ideológicos ajenos al visitante, no los representa y no los considera, ya que la historia de las instituciones culturales ha estado marcada por las jerarquías 
y las decisiones a puertas cerradas. Al respecto, las profesionales de museos coinciden en que esto es así, enfatizando que funcionan de acuerdo a sus protocolos, comunicándolo a través de los canales oficiales y webs institucionales.

Por otra parte, hay imaginarios que ofrecen otra lectura positiva de las instituciones culturales, como es el caso del valor educativo y promocional de la cultura y que, para Ca, permitirían "a los jóvenes elegir entre un abanico de posibilidades para aprender más allá de lo que el común de las personas sabe o cree saber acerca de lo que ocurre a nuestro alrededor”. Por lo tanto, podría concluirse que la formación de los ciudadanos se hace desde la contribución cultural, la calidad de las muestras, el acompañamiento para conseguir contactos significativos y la fidelización "para educar y mostrar realidades" (Ja). Este imaginario se sustentaría en la necesidad de los jóvenes visitantes por formarse en la cultura visual.

\section{Los museos y sus imaginarios acerca de los jóvenes}

El primer imaginario manifestado es que el público joven interesado en arte y cultura es más diverso y más numeroso que hace veinte años y desde ese posicionamiento reconocen al público joven y sus áreas de interés, implicándolos con fines específicos, lo que, a la vez, hace necesario contar con mayores espacios, programas y condiciones para que los sujetos puedan desarrollar actividades de exploración conducentes a la formación de la cultura visual. Pero todo imaginario es dinámico y cambiante (Martínez, 20I I), por lo tanto, es posible que la percepción acerca de los museos se enriquezca o empobrezca, pues es una actividad llena de tensiones dinámicas.

Un segundo imaginario es que los jóvenes visitantes, en general, están muy interesados en el conocimiento, entendimiento y creación del arte chileno. Esta referencia tiene que ver las definiciones de público que se hacían en páginas anteriores. Son universitarios y público joven ligado a actividades artísticas. Ellos no solo buscan conocer y ver, sino que experimentar, crear y hacer circular sus producciones, lo que implica un acercamiento concreto a la educación de la cultura visual que, aunque supeditada a las colecciones y las actividades habituales del museo, conecta al sujeto con la vivencia de la obra 
y a su discurso, ampliando el lenguaje al construir sentido para los conceptos y elaborar otros en la profundización propia de la experiencia artística. Pero también "nos visitan otros que no tienen capacidad para percibir una imagen, sea de la televisión, desde los medios o una imagen pictórica” $(\mathrm{Pa})$. El imaginario del visitante que no sabe nada plantea al museo un desafío, pues ante el hecho de que hay "unos jóvenes que no saben ni siquiera leer una imagen, que nunca han desarrollado la percepción visual” ( $\mathrm{Pa}$ ), Para ellos el museo es un gran libro, taller, lienzo y biblioteca para alfabetizarse.

\section{Los museos y sus imaginarios de cultura}

El imaginario de museo elitista fue uno de los dominantes hasta hace poco, con acceso restringido por el costo de la entrada y con el requerimiento de un capital cultural a los visitantes para entender el arte y las colecciones. Esa idea ha ido cambiando con el paso del tiempo hacia una redefinición de sus políticas. La nueva misión tiene que ver con el acceso y la inclusión, que al "ser espacio para todos, significa entender que la cultura versus dinero no tiene mucha conexión” (Pa). Este cambio ha tejido las primeras hebras de la democracia cultural. Se espera que esta idea sea socializada con los estudiantes para ir cambiando los imaginarios que hoy se tienen acerca de los museos metropolitanos, cuyas entradas van desde los $\$ 500$ a $\$ 1000$, y con días de horarios gratis. Así, cuando los jóvenes hablan de falta de acceso, quizá, lo hacen desde un imaginario sin actualizar, que al compararse con otras áreas de la cultura, por ejemplo, el cine, resulta con un precio muy bajo y, en consecuencia, accesible casi para cualquier ciudadano.

Una de las entrevistadas de museo señala que la institución se percibe desde un imaginario de invisibilidad. Esta percepción entra en abierta contradicción con el imaginario anterior, pues la invisibilidad está condicionada por la arquitectura y por el foco de las colecciones, de tal modo que construir una justificación para el sentido y cantidad de las visitas desde este imaginario a priori limita su sentido de proyección cultural e inhabilita la creatividad y el marketing que es necesario manejar en estos casos. Aun así, como lo señaló una de las entrevistadas, las visitas nunca faltan, porque hay visitantes que conocen el lugar, pero los de la provincia, que no conocen el sector, 
pierden mucho tiempo en la búsqueda. "De repente llegan grupos de 45 estudiantes con sus profesores y no saben encontrarnos estando a una calle del museo" ( $\mathrm{Pa}$ ). Una de las preocupaciones del museo es poder ser ubicado con facilidad. "Nosotros queremos que el imaginario del público cambie hacia este espacio, queremos que nos encuentren, cualquier persona, incluso ciegos y sordos" (Pa).

La percepción de institución precaria es otro de los imaginarios. Se cree que la imagen que se proyecta no se relaciona con el valor de sus colecciones y con el significado histórico que el museo tiene. Es una institución del pasado que busca actualizar su imaginario en el sentido de querer ser moderna en su gestión, pero, a la vez, de un gran espesor histórico al guardar importantes colecciones de la historia y la identidad nacional. Ve comenta: "Nos gustaría ser vistos como un museo que conserva nuestro pasado, que habla sobre nuestras raíces o nuestra formación como país, que muestra valores asociados a personajes claves en nuestro pasado, pero que también nos hace preguntar respecto a nuestro presente y también nos provoca cierta participación”.

\section{Los museos y su relación con el CNCA}

Este tema se plantea a raíz de la necesidad de conocer el nivel de interrelación de las instituciones culturales entre sí, sus cruces conceptuales, políticas, leyes, etc. La relación de los museos con el CNCA como la institución promotora en gran escala de las políticas culturales no está muy clara para las entrevistadas. Argumentan que como como museo "estamos más hacia el lado de la DIBAM que del CNCA” (Ve). Sin embargo, no se alude a que la DIBAM está alineada con el CNCA y con el Consejo de Monumentos, entidades motoras de la cultura en Chile, lo que refleja desconocimiento y falta de rigor técnico. Expresa Pa que "no tiene idea de cuáles son las políticas que tiene en este momento el Consejo Nacional de la Cultura y las Artes". A esto, Ve agrega que "en términos de políticas no nos llega mucho, participamos por ejemplo en la Ley de Donaciones Culturales, pero no sé si brota del Consejo de la Cultura”.

En este sentido, la respuesta de los estudiantes es más prometedora, manifestando un conocimiento bastante más aproximado que las 
respuestas anteriores. Por ejemplo, Na dice: "No tengo muy claro en qué consiste el Consejo Nacional de la Cultura y las Artes. Solo he escuchado su nombre y un par de aportes que les ha otorgado a los artistas locales para ayudarles a desarrollar su trabajo”. Llama la atención, porque $\mathrm{Na}$ es estudiante de Artes Visuales y un tema como este debería ser de su dominio. Sin embargo, Ka, estudiante de Educación Parvularia, señala que "es el organismo estatal que promueve el desarrollo de las artes en Chile, principalmente mediante financiamiento y actividades que las acerquen a la ciudadanía". Ca dice que: "Sé lo que es y creo que la forma como podría ayudar al país es aumentar el fomento a las actividades culturales para la infancia. Si existe una formación de ciudadanos involucrados y partícipes de la propia formación cultural, también aumentará la demanda en cuanto a la creación de experiencias y oportunidades culturales”. Queda demostrado que las percepciones que se tienen se ajustan a una comprensión aceptable sobre la naturaleza y fines de las instituciones culturales.

La diferencia de respuestas de los jóvenes y las profesionales de museos es notoria, lo que se puede explicar por los niveles de expectativa y situación de quien contesta. Los que se están formando manifiestan interés por conocer lo nuevo, no obstante, hay quienes desde otra condición cultural y laboral, miran el mismo asunto filtrado por la rutina, la costumbre y la comodidad del discurso. En estas diferencias subyacen también perspectivas positivas, puesto que conocer los relatos de diferentes actores posibilita visualizar márgenes, mecanismos y culturas inherentes a instituciones e individuos.

\section{¿Es posible la cultura visual juvenil?}

Cuando se les pregunta a los jóvenes acerca de si tienen cultura visual, la mayoría expresa ideas positivas al respecto, destacándose en las percepciones de los estudiantes de Artes Visuales un nivel significativo de comprensión en temas de visualidades y sus lecturas. Por lo tanto, se puede sostener que estos estudiantes por la naturaleza de su formación, por la cultura implícita de los programas que estudian, están en mejor pie para entender y hacerse más rápido y sostenidamente de cultura visual. 
La generación de la cultura visual implica un entrenamiento construccionista, pues desde diversos fragmentos culturales (la publicidad, el diseño, la artesanía, etc.) se ejercitan capacidades como la problematización, la revisión, la captación de referencias, la creación, la recreación, el establecimiento de relaciones visuales, etc., susceptibles de transformarse en sustratos para la generación de procesos productivos, que, a la vez, conllevan una estructura discursiva y conceptual consistente que permite "crear imágenes y hacer relaciones entre lo que veo y lo que hago" (Ro). Complementa esta idea Cam, estudiante de Educación Parvularia, quien sostiene que "la cultura visual es la forma de entregar información o comunicarse a través de imágenes más que con palabras (...) hoy en día la cultura es muy diversa y asimismo la forma de expresarla y de interpretarla”, lo que indica que no solo las áreas afines otorgan la cultura, también lo hace el posicionamiento cultural del individuo y los filtros culturales a través de los cuales lee la realidad social.

El museo y las instituciones culturales, en general, son el espacio desde el cual se leen estas interferencias. Fra alude a la cuestión del bagaje cultural, entendiéndolo como el "conjunto de saberes que un joven posee en relación con sus imaginarios, que deberían manifestarse en nuestra personalidad, siempre que poseamos interés en el arte (...), permitiendo que conozcan al menos un poco de todo". Pero no solo a través de la producción material se puede demostrar la cultura visual, se puede hacer con la teoría, la empírica y la política, toda vez que hay que defender una idea, un proyecto, a nivel de exposiciones, fundamentaciones orales o discursivas. "Más que nada se ve cuando te preguntan: ¿conoces este artista?, si lo conozco, quizás puedo entender otra cosa que haga, yo creo que va por ahí” (An).

Los demás participantes se declaran poseedores de una cierta cultura visual y entienden que les ayuda a tener una postura informada ante el mundo de las visualidades, contribuyendo a enriquecer su personalidad. Ca comenta: "No me considero una persona con cultura visual, porque no sé distinguir los estilos artísticos de la obra que en ese momento estoy mirando, solo lo hago porque me gusta asombrarme con la genialidad y creatividad de los artistas que hay 
detrás de esas obras, y las emociones o recuerdos que me provocan lo que estoy mirando", a lo que Ja agrega: "Tengo conocimientos sobre aquello, y lo he aprendido aquí en la universidad”.

Estas percepciones son un buen indicador para un acercamiento consciente al mundo de lo visual, aunque solo sea reflejo de lo que los jóvenes han visto en las aulas universitarias o en los museos como espacio central de esta investigación. Pensar que la compresión y apropiación cultural del lenguaje de las visualidades es un acto que solo se puede desarrollar en las instituciones culturales, es mirar en menos un fenómeno que es transversal a muchos escenarios y que se manifiesta en muchos soportes, aparte de los museales.

Por otro lado, los jóvenes entrevistados, incluso, proponen cómo debería ser un sujeto poseedor de cultura visual, estimando que las manifestaciones básicas de ese capital deberían darse en "una persona que conozca algunos elementos básicos de la historia del arte y la estética, que tenga las herramientas para decodificar el arte visual que está apreciando (...) manteniendo como hábito la visita a centros de exposiciones y ejercitando habitualmente sus conocimientos en torno al tema, leyendo, por ejemplo" (Ka).

\section{Los museos y su influencia en la cultura visual juvenil}

A pesar de la aparente contradicción, la actitud crítica ante los programas unilaterales, la inaccesibilidad, el elitismo, la falta de representatividad e inclusión juvenil, se reconoce que los museos hacen una contribución al desarrollo de la cultura visual juvenil. Desde esta perspectiva, la valoración institucional no merma la problematización crítica de los modos, estilos y discursos con los que opera.

La mirada esperanzadora que se asocia con la valoración de las instituciones (museos) puede tener su relato en el imaginario social, donde se ven como entidades representantes de la cultura chilena, históricamente hablando. De ahí que se las entienda como espacios que de alguna manera educan, en este caso en la cultura visual. Por eso, "cada vez que las visito me quedo con algunos elementos que contribuyen a mi desarrollo como persona, como ciudadana, y como 
futura educadora infantil, siempre me dejan pensando en algo acerca de los temas que se abordan” (Ka).

La percepción macro que comparte Ka se complementa con el mundo de las experiencias y aprendizajes que cada sujeto por sí solo o con otros va generando. La naturaleza diversa, la trascendencia, la curiosidad y la apropiación de saberes y prácticas ayudan a entender no cuánto y de qué se sabe, sino lo que se hace con lo que se sabe, y para qué puede servirle a un joven.

\section{Lo que dicen los museos acerca de la cultura visual}

Desde los museos, la contribución a la educación de la cultura visual puede verse en la adaptación e implementación de diversos métodos provenientes del mundo de la empresa y aplicados a un museo de artes visuales. Se busca con ello desarrollar el pensamiento visual, como una vía primaria para la educación de la cultura visual. Estas medidas son la respuesta a la lectura de un público sin ninguna formación, pues, como menciona $\mathrm{Pa}$, "nuestra gente, nuestros niños, nuestros jóvenes o nuestros ciudadanos no tienen el desarrollo de su pensamiento visual". La profesional no especifica cuáles son las estrategias ni los resultados obtenidos a la fecha, pero puede inferirse que la fidelización y las opiniones favorables que han dado los entrevistados, en cierto modo, es la respuesta a estas nuevas aplicaciones.

El otro museo consultado centra su aporte en cultura visual exclusivamente, en el valor histórico y estético de sus colecciones, lo que permite al visitante no solo construir percepciones desde los objetos, sino que, además, generar relatos y narrativas respecto de la historia de los mismos. Posición que va en la línea de las grandes ideas de la cultura visual y educación de Hernández (2010). En consonancia con esto, la profesional de museos, Ve, manifiesta que "son expresiones artísticas mezcladas con las expresiones históricas de objetos, entonces el trabajo con las formas, con los colores, con la gráfica, el acceso a eso, es estimulante para que la persona recuerde lo que vio y también de alguna manera lo utilice en sus propias creaciones artísticas o en otras visitas”. El capital cultural del museo está en sus objetos, esto es muy motivante para el desarrollo del pensamiento visual y la cultura visual que los visitantes pueden construir. 


\section{Conclusiones}

I. El concepto institución cultural se refiere al amplio espectro de entidades que tienen como fin colaborar en la cultura y educación no formal. Sin embargo, la mayoría de los ocho estudiantes entrevistados entendió como institución cultural a los museos. Quizá esto pueda explicarse por la temporalidad de su imaginario cultural, situándolos como el eje de la cultura.

2. Respecto de la cultura visual, los jóvenes que estudian artes visuales o arquitectura, tienen un conocimiento y comprensión más acabado, lo que se puede explicar por el contexto, que apoya fuertemente la construcción de percepciones profesionales amplias y variadas y por el enriquecimiento paulatino del lenguaje visual y sus prácticas.

3. En relación con la cultura, los jóvenes de carreras como Educación Parvularia y Educación Básica, tienen un manejo más concreto, lo que evidencia un acervo cultural básico en relación directa con el sentido de su formación profesional.

4. La situación es más crítica en el caso de los profesionales de museos. Estos asocian la cultura visual con ciertos contenidos museales relacionados con la percepción visual. No se expresa conocimiento técnico ni referencias teóricas que sustenten sus percepciones y políticas de trabajo al respecto.

5. Lo mismo sucede con el concepto de imaginario, ante el cual los estudiantes y los profesionales de museos atribuyen definiciones y comprensiones ambiguas. Es posible que esto se deba a que, tanto en los ámbitos de estudio de los jóvenes, como en los lugares de trabajo de los profesionales de museo, no sea un concepto de uso corriente.

6. Algo tan relevante como la educación y la mediación en museos es un tema no resuelto. Reconocen las profesionales que la Pedagogía es lo más importante en cuanto modo y fin para ayudar a un visitante en su tránsito hacia el objeto museal. A vez se justifican, señalando que en Chile no existe la profesión de educador de museos y, por lo tanto. todo lo que se hace al respecto es un poco a medias.

7. Llama la atención la desinformación que manifiestan los entrevistados acerca de los programas culturales. Dicen no 
conocer las actividades culturales ofrecidas al público, lo que no guarda relación con la información publicada por las webs de museos, bibliotecas y el CNCA sobre la materia.

8. Se aprecia una actitud resistente por parte de los jóvenes, que esencialmente está relacionada con la falta de inclusión y representación. Dicen que los diseños y programas de los museos no consideran los intereses reales de los jóvenes, no atienden lo que hace falta, no incluyen a la gente, no toman en cuenta la identidad ni consideran el territorio, y lo que es aún más crítico, aducen elitismo.

9. Los jóvenes no reclaman una participación a nivel biestamental, sino ser considerados desde y con su realidad en los diseños de programas culturales, de tal modo que la oferta cultural tenga un carácter representativo, un eco masivo y que eduque desde las necesidades de cultura visual.

I0. Los imaginarios de los jóvenes acerca de las instituciones culturales están asociados a élites sociales, cultura elevada, falta de acceso, participación y lejanía de los jóvenes. No obstante, reconocen que son lugares que, desde lo poco que ofrecen, permiten a los interesados educarse en la cultura visual.

II. Los jóvenes piensan que los museos deben ser instituciones que, desde sus planes y programas, deben integrar y llevar la cultura a todos los ciudadanos del país, abriendo espacios para una verdadera democracia cultural.

I2. Los museos no piensan en los jóvenes sino en términos de definiciones etarias y tendencias de consumo cultural, inquietudes, participaciones e intención creativa, enfatizando que algunas de estas características hacen que ciertos grupos sean más proclives que otros a educarse en lo visual y a desarrollar más profundas y activas participaciones en su cultura visual.

13. Los imaginarios de los museos están asociados a lo que conceptual y (a lo que) espacialmente representan, destacándose la imagen arquitectónica, su orientación cultural, la accesibilidad física y la (in)visibilidad en la geografía urbana.

I4. Otras construcciones sociales devenidas de imaginarios se orientan a la necesidad de ser reconocidos en sus comunidades inmediatas, como referentes en su rubro. 
I5. Por su naturaleza cultural, los museos consultados están orientados hacia ciertas áreas de las artes visuales, la iconografía y las imágenes históricas. Como tal cada actividad desarrollada conlleva directa o indirectamente un fin educativo. Los jóvenes reconocen que los planes y programas ayudan a formarse en la cultura visual, valorando los dispositivos materiales, el contexto, la relación con la gente y el sentido de vinculación generado a través de las visitas sucesivas.

I6. Pero el museo no tiene como fin educar la cultura visual, esto se consigue en forma indirecta, intentando colocar a un visitante en relación con una obra o artefacto visual, asistido o acompañado por alguien que debería orientar hacia lecturas críticas.

I7. La relación constante de los jóvenes con las instituciones culturales va generando actitud, conciencia, educación del ojo, desarrollo intelectual y sensibilidad estética, lo que posibilita la construcción de un nuevo lenguaje para hablar, expresar y dar sentido a estas nuevas construcciones.

\section{Referencias bibliográficas}

Bellido, M. (200I). Arte, museos y nuevas tecnologías. Gijón: Trea.

Cabral, M. (2008). Los museos y el público joven. Museos, educación y juventud. Memorias del V Encuentro Regional de América Latina y el Caribe sobre Educación y Acción Cultural en Museos CECA - ICOM. Pp. 23-29.

Castoriadis, C. (2007). La institución imaginaria de la sociedad. Buenos Aires: Tusquest. Hernández, F. (2010). Educación y cultura visual. Barcelona: Octaedro.

Jaramillo de Carrión, M. (2008). Del museum al foro y el teatro dentro del parque: una propuesta para reflexionar. Museos, educación y juventud. En Cortés, A., Memorias del V Encuentro Regional de América Latina y el Caribe sobre Educación y Acción Cultural en Museos CECA - ICOM (pp. 8-I3). Bogotá: Ministerio de Cultura, Museo Nacional de Colombia y Red Nacional de Museos.

Limón, M. \& Crespo, J. (2002). Grupos de debate para mayores. Madrid: Narcea.

Lindón, A. (2007). Diálogo con Néstor García Canclini. ¿Qué son los imaginarios y cómo actúan en la ciudad? EURE, XXXIII (99), 89-99.

Martínez, J. (20I I). Las Artes Visuales y la educación de la cultura visual. Cátedra de Artes, 9, 13-28. 
Mitchell, W. (2003). Mostrando el ver: Una crítica a la cultura visual. Estudios Visuales, I, 17-40.

Padró, C. (2005). Museos y educación artística: redes de paso, encrucijadas difusas, zonas de conflicto. En R. Marín (Ed.), Investigación en educación artística pp. (495-508). Granada: Universidad.

Pintos, J. (2004). Inclusión y exclusión. Los imaginarios sociales de un proceso de construcción social. Semata, Ciencias Sociales y Humanidades, I6, I7-52.

Rubiales, R. (2008). Breves notas sobre los jóvenes y la experiencia museal. Museos, educación y juventud. En Cortés, A., Memorias del V Encuentro Regional de América Latina y el Caribe sobre Educación y Acción Cultural en Museos CECA - ICOM (pp. 19-22). Bogotá: Ministerio de Cultura, Museo Nacional de Colombia y Red Nacional de Museos. 